\title{
Astronomical Publications
}

\section{Philippe de la Cotardière}

14 rue de Castellane, F-75008 Paris, France

The glory of the heavens is available to everyone, and anyone, whatever their level of scientific knowledge, is able to appreciate their beauty, poetry and mystery. They are a window to the inaccessible and the unknown and have always attracted attention and aroused Man's curiosity. This natural fascination for the universe is a precious card in the popularization of astronomy. Three centuries ago, Fontenelle knew how to exploit it in his Entretiens sur la pluralité des mondes, which made him famous. Many others followed him in the 18th and 19th centuries, of which Camille Flammarion may be mentioned especially. Printings of his famous Astronomie Populaire grossed 130000 copies between 1879 and 1924.

Science nowadays does not arouse the same enthusiasm as it did in Flammarion's day. Since the development of astrophysics, astronomy has become ever more complex, making the task of those who wish to explain new developments more difficult.

It seems, however, that the public's curiosity about astronomy has never been as great: everywhere you find lecture halls full, observatories swollen with visitors, planetariums sold out. Undoubtedly, this does in part arise from the interest that I mentioned at the beginning, but it is also caused by the media's response to the exploration of the Solar System in the last twenty years by spacecraft, and to the the spectacular discoveries that they have made. Finally, it perhaps also stems from the general availability of amateur-sized instruments, thanks to which anyone can now enjoy the delights of observing the sky with a refractor or reflector at a modest price.

This public interest in astronomy has not escaped publishers. Some recent popular works have had record printings and at long last we can see, in some bookshops, a range of astronomy books that rivals the number on astrology. The books available fall into approximately three categories: encyclopedic works, heavily illustrated and showing a general view of the universe; smaller books, moderately or much less profusely illustrated, that describe recent developments in a specific field such as cosmology; and practical books (observation of the sky and instrumentation), at various levels.

A detailed examination of books in each group shows that certain aspects of astronomy are preferred, because they have been exploited more by the media. Recent discoveries about the Solar System or modern views of cosmology with 
their description of the Big Bang, undoubtedly benefit from favourable treatment. Astrometry, on the other hand, remains completely overshadowed.

We must also deplore the absence of elementary works designed specifically for young people. Works for children are, in general, picture books where the text has just the role of providing an explanation of the pictures. One of the areas in which popularization by means of books ought to concentrate, is that of documentary books for children, all the more as such a well-executed book is also bound to be read by their parents.

The easy solution, for a publisher, is to buy rights to a book that has sold well in other countries, translating it, or perhaps adapting it. Until recently this was, unfortunately, the most common course in France, sometimes with dreadful results (with numerous errors in translation). But now we are seeing a very definite movement towards works that originate here. For practical works, associations representing amateur astronomers or some of their members, known for their work, are the sources favoured by publishers, who in effect know that the associations are useful contacts able to promote such works.

For the encyclopedic works that require various contributors and for popular works on some specific theme, the choice of authors is paramount, but often delicate. Some eminent scientists may prove to be talented popularizers: Eddington and Gamow were, for instance. Others have difficulty in getting their message across, the problem being not so much that of being simple as of being inspiring: readers of a popular book always need to be stimulated by what they are reading. My personal experience leads me to state that the best results may arise from close collaboration between a researcher and a scientific journalist. Scientists are often tempted to pay excessive attention to basics and to neglect the overall impression, because, good intentions notwithstanding, they are thinking of the reaction of their peers, and not that of their readers. This is one of the problems that collaboration between a researcher and a journalist can avoid.

Whatever happens, a popular work will not be a success unless it is written with enthusiasm. If the author is bored by writing a book, then the reader will be even more bored by reading it. Remember Camille Flammarion, whose enthusiasm is quite obvious on each page of his work.

Illustrations are an important part of modern, popular-astronomy books. There are rich resources for Solar-System objects, thanks to the many photographs obtained by spaceprobes, but for galactic or extragalactic objects, on the other hand, the same pictures are found in one book after another. Luckily an injection of new life is occurring with photographs from major observatories in the southern hemisphere. Artwork too, often plays an important part in understanding the text and considerable effort has been given to this aspect in many recent books.

Apart from books, the interest that astronomy has for a wide public, avid to hear about the latest information, explains the presence of articles about recent developments in astronomy that can be found in must issued of news or popularscience magazines at all levels.

Unfortunately, magazines specifically devoted to the popularization of astronomy mostly suffer from being the journals of organisations that are non-commercial, 
and which neither have the technical expertise nor the financial resources to ensure a wide circulation, although the journals themselves provide information of the highest standards.

In default of being able, without external help, in issuing publications that have a wide circulation, amateur associations can make regular contributions to media that do reach a wide public. Items of the "month's sky" type can find a place in the press, or even on television. Some large newspapers already carry this sort of item, either in collaboration with individual astronomers or associations. Developments in amateur astronomy can only prompt the editors of newspapers to such ideas. Conversely, regular publications of this sort greatly help to popularize astronomy.

Other links can be forged with publications that reach readers to whom astronomy might be a source of interest. Avid photographers, computer buffs and handymen all have their own magazines, and each of these could lead to ideas for articles able to contribute to the popularization of astronomy.

Popularization of astronomy in books and magazines is a never-ending task, given the constant progress in knowledge, and all the enigmas that arise new discoveries. Current events are a distorting mirror that often lead to emphasis on minor subjects. But astronomical events also allow one to get back to basics. This is all the more necessary when we recall the results of a survey made several years ago by the Centre National d'Etudes Spatiales, which showed that one French person in three over fifteen still believes that the Sun moves round the Earth. 